\title{
Population of Eospalax Baileyi Pallas and its Controls with
}

\section{Compound Poison Bait's}

\section{Zhang $Y$ and Yang $K^{*}$ \\ Southwest Minzu University, China}

*Corresponding author: Kong Yang, Institute of Qinghai-Tibetan Plateau, Southwest Minzu University, China, Email: lx-yk@163.com

\section{Research Article \\ Volume 2 Issue 5}

Received Date: August 05, 2019

Published Date: September 05, 2019

DOI: $10.23880 /$ izab- 16000170

\section{Abstract}

Pest control is still the important work to manage the grassland in West China. E. baileyi Pallas is the main rodent in Qinghai-Tibetan Plateau grassland, so population density of E. baileyi Pallas was continuously investigated from 2015 to 2016 based on the previous works of 2013 and 2014, compound poison baits effects were tested on E. baileyi Pallas. The block-open method was used to survey the population density with three repeat grids. Rapeseed oil and peanut oil was used as attractant to make compound poison, and then determine the compound poison bait effects on E. baileyi Pallas. The density was 37.12 and 35.32 individuals $/ \mathrm{hm}^{2}$ in 2015 and 2016, respectively. The results showed that the average feeding rate of rapeseed oil was $76.7 \%$, which was significantly higher than that of peanut oil with $65.12 \%(P<0.05)$. The average killing rate of poison bait without attractant was $74.68 \%$, which was significantly lower than the rate of poison bait with attractant $(88.85 \%, \mathrm{P}<0.01)$. The average density of E. baileyi Pallas in Hongyuan County was 36.22 individuals $/ \mathrm{hm}^{2}$ which indicated that the pest was highly harmful to the grassland. The effect of D-type kreotoxin poisoning E. baileyi Pallas could be significantly improved with the attractant.

Keywords: Hongyuan County; Myospalax Baileyi Pallas; D-Type Kreotoxin; Attractant

\section{Introduction}

Sichuan northwest prairie distributes in three autonomous prefecture including ganzi, aba and liangshan, sichuan province, constitutes northwest sichuan pastoral area which belongs to one of the five major pastoral areas of China. At present, due to the climate change and the unreasonable utilization, rats living in this grassland are rampant, and lead to grassland degradation, loss of productivity, and even desertification [1]. Grasslands in China has more than 100 kinds of rats and mice in which common rodent species are Ochotona curzoniae Hodgson, Myospalax baileyi Pallas, Rhomobomys opimus Lichtenstein, Meriones unguiculatus Milne Edwards and so on. These kinds of rodents mainly distribute in sichuan, gansu, Tibet, qinghai and other 13 provinces (area) [2]. Among them, Ochotona curzoniae Hodgson Myospalax baileyi Pallas is characteristic of the qinghai-tibet plateau rats [3]. At present, chemical medicine is used to pest management, and its poisoning effect is closely related to the rodents acceptance of poison bait $[4,5]$. Type D botox poison bait was widely 


\section{International Journal of Zoology and Animal Biology}

used in grassland of qinghai province to control pest. The results showed that the poison bait has good palatability, high deratization effect. Moreover, Type D botox poison bait has lots of advantages including environment friendly, no secondary poisoning and short life-span in giving nature conditions.

In order to long term surveillance the density of Myospalax baileyi Pallas and improve the efficacy of Type D botox controlling Myospalax baileyi Pallas, we surveyed the plateau zokor density during the period of 2015-2016 based on previous works of 2013 and 2014, designed different types attractants matched with type D botox, and checked the effects of poison baits on Myospalax baileyi Pallas.

\section{Materials and Methods}

\section{Rodent's Density Survey}

Survey area locates in the qinghai-tibet plateau between $101^{\circ} 51^{\prime} \sim 103^{\circ} 23^{\prime} \mathrm{E}, 31^{\circ} 51 \sim 33^{\circ} 19^{\prime} \mathrm{N}$. The average elevation is above $3600 \mathrm{~m}$, and belongs to plateau monsoon climate with extreme minimum temperature$36^{\circ} \mathrm{C}$. 3 samples (Table 1 ) area were randomly selected yearly, block-open method was used to determine effective holes, and the whole coefficient and population density.

\section{Attractants and Bait Components}

Baits and attractants were in divided into 5 groups based on the components (Table 1).

\begin{tabular}{|c|c|c|}
\hline No & Baits & Attractants \\
\hline A & oats & Salt, onion, white sugar, rapeseed oil \\
\hline B & oats & Salt, onion, white sugar, peanut oil \\
\hline C & oats & control \\
\hline D & carrrots & Salt, onion, white sugar, rapeseed oil \\
\hline E & carrots & control \\
\hline
\end{tabular}

Note: The components' proportions were: sugar (350 g/50 kg), oil (300 g/50 kg), salt (350 g/50 kg), green onion (2 $\mathrm{kg} / 50 \mathrm{~kg}$ ).

Table 1: Different groups of attractant components and baits.

Totally 30 grids with size $15 \mathrm{~m} \times 15 \mathrm{~m}$ were established, each kind of bait feeding 6 grids.

Feeding rate $(\%)=$ feeding hole numbers /effective hole numbers x $100 \%$

\section{Attractant and Type D Botox Compound Poison Bait as well as its Effects}

Component of poison bait was showed in table 4 , and bait would be feeded 12 hours later.

Totally 48 grids with size $15 \mathrm{~m}$ x $15 \mathrm{~m}$ was set up, and then bait was piped into the hole about $60 \mathrm{~cm}$ faraway entrance following sealing the hole. The dead rate of rodent was checked 7 days later and 15 days later,

Dead rate of rodent $(\%)=($ effective number of hole before feeding baits- effective number of hole after feeding baits)/ effective hole number before feeding baits $\times 100 \%$

\section{Results}

\section{Myospalax Baileyi Pallas}

The effective hole coefficient and population density were shown in Table 2.

\begin{tabular}{|c|c|c|c|c|c|c|}
\hline $\begin{array}{c}\text { Sampling } \\
\text { time }\end{array}$ & Sites & $\begin{array}{c}\text { Grids' } \\
\text { size/hm }\end{array}$ & $\begin{array}{c}\text { Opening holes } \\
\text { number }\end{array}$ & $\begin{array}{c}\text { Effective holes } \\
\text { number }\end{array}$ & $\begin{array}{c}\text { Coefficient of } \\
\text { hole }\end{array}$ & $\begin{array}{c}\text { Population } \\
\text { density/(individual/hm2) }\end{array}$ \\
\hline \multirow{4}{*}{2015} & site1 & 0.25 & 41 & 29 & 0.34 & 39.44 \\
\cline { 2 - 7 } & site2 & 0.25 & 39 & 31 & 0.35 & 43.4 \\
\cline { 2 - 7 } & site3 & 0.25 & 33 & 23 & 0.31 & 28.52 \\
\cline { 2 - 7 } & average & 0.25 & $37.67 \pm 3.4$ & $27.6 \pm 3.40$ & $0.33 \pm 0.017$ & $37.12 \pm 6.29$ \\
\hline \multirow{4}{*}{2016} & site1 & 0.25 & 33 & 25 & 0.33 & 33 \\
\cline { 2 - 7 } & site2 & 0.25 & 35 & 25 & 0.33 & 33 \\
\cline { 2 - 7 } & site3 & 0.25 & 41 & 27 & 0.37 & 39.96 \\
\cline { 2 - 7 } & average & 0.25 & $36.33 \pm 3.40$ & $25.67 \pm 0.94$ & $0.34 \pm 0.019$ & $35.32 \pm 3.28$ \\
\hline
\end{tabular}

Table 2: The population density of Myospalax baileyi Pallas in Hongyuan County. 
The Feeding Rate with Different Type of Bait Component was Showed in Table 3

\begin{tabular}{|c|c|c|c|c|}
\hline No. & Number of effective hole & $\begin{array}{c}\text { number of feeding hole 3days } \\
\text { later }\end{array}$ & $\begin{array}{c}\text { number of feeding hole 6days } \\
\text { later }\end{array}$ & $\begin{array}{c}\mathbf{6} \mathbf{d} \text { feeding } \\
\text { rate/\% }\end{array}$ \\
\hline A & 39 & 18 & 30 & $76.92^{\mathrm{a}}$ \\
\hline B & 43 & 20 & 28 & 65.12 \\
\hline C & 20 & 6 & 13 & 65 \\
\hline D & 34 & 17 & 26 & $76.47^{\mathrm{a}}$ \\
\hline E & 29 & 13 & 19 & 65.52 \\
\hline
\end{tabular}

Note: The lower-case letter in the same row means there is a significant difference $(\mathrm{P}<0.05)$; $\mathrm{C}$ is the control of $\mathrm{A}$ and $\mathrm{B}$; $\mathrm{E}$ is the control of $\mathrm{D}$.

Table 3: The feeding rate for different attractant mixed bait.

\section{The Dead Rate Of Different Kinds of Poison Bait Upon Rodents}

The average dead rate of four groups with attractants was $88.85 \%$, whereas the control was $74.68 \%$, $\mathrm{t}$ test showed statistical significance $(\mathrm{P}<0.01)$ between them (Table 4).

\begin{tabular}{|c|c|c|c|c|c|c|c|}
\hline & No. & $\begin{array}{c}\text { Concentration of } \\
\text { D-type kreotoxin }\end{array}$ & Baits & $\begin{array}{c}\text { Number of } \\
\text { effective } \\
\text { hole(before) }\end{array}$ & $\begin{array}{c}\text { Number of } \\
\text { effective hole } \\
\text { 7days later }\end{array}$ & $\begin{array}{c}\text { Number of } \\
\text { effective hole } \\
\text { 15days later }\end{array}$ & $\begin{array}{c}\text { Dead rate of } \\
\text { rodent 15days } \\
\text { later (\%) }\end{array}$ \\
\hline \multirow{4}{*}{ Attractants } & A1 & $0.15 \%$ & oat & 27 & 8 & 3 & 88.89 \\
\cline { 2 - 8 } & B1 & $0.10 \%$ & oat & 30 & 4 & 2 & 93.33 \\
\cline { 2 - 8 } & C1 & $0.15 \%$ & carrot & 26 & 10 & 4 & 84.61 \\
\cline { 2 - 8 } C1 & $0.10 \%$ & carrot & 70 & 17 & 8 & 88.57 \\
\hline \multirow{5}{*}{ Control } & E1 & $0.15 \%$ & oat & 34 & 11 & 6 & 82.35 \\
\cline { 2 - 8 } & F1 & $0.10 \%$ & oat & 41 & 17 & 11 & 73.17 \\
\cline { 2 - 8 } & G1 & $0.15 \%$ & carrot & 31 & 11 & 9 & 70.98 \\
\cline { 2 - 8 } & H1 & $0.10 \%$ & carrot & 36 & 15 & 10 & 72.22 \\
\hline
\end{tabular}

Note: The colza oil was added into the control group as an attractive component.

Table 4: Dead rate of rodent poisoned by attractants and D-type kreotoxin.

\section{Discussion}

\section{Attractants Component and its Effects}

Chemical rodenticide is the main way of controlling pest, and its efficiency is affected by the rat species, natural factors, the stability of rodenticide as well as palatability of poison bait [5]. This study using oat and rapeseed oil mixture significantly improve the feeding rate $(\mathrm{P}<0.05)$, the reason may be that the rapeseed oil has more rich flavor substance which lure the rodent effectively.

\section{The Effect of Different Compound Poison Bait Containing Different Concentration of Type D Botox and Attractants}

The compound poison bait containing Type D botox and attractant significantly improved type D botox deratization effect. Our attractant was made of scent and flavor food agent. In this way, it attracts Myospalax baileyi
Pallas and increases their intake of poison bait, which leads to greatly reduce the waste of bait and also significantly increase the effect of poison.

\section{Conclusion}

The average density of E. baileyi Pallas in Hongyuan County was 36.22 individuals $/ \mathrm{hm}^{2}$ which indicated that the pest was highly harmful to the grassland. The effect of D-type kreotoxin poisoning E. baileyi Pallas could be significantly improved with the attractant. In the future, we would like to continuously survey the dynamics of populations' density and its driving reasons, and illustrate the spatial-temporal patterns, which will make insight into the mechanism and controlling strategy.

\section{Acknowledgements}

This research was funded by the national natural science foundation of China (31070380). The innovation 


\section{International Journal of Zoology and Animal Biology}

research team program of the education department of Sichuan Province, 14TD0049, The Fundamental Research Funds for the Central Universities, Southwest University for Nationalities, 2019XMJXPY07.

\section{References}

1. Yu H LFan J W, Li Y Z, Shi W J (2018) Effects of Myospalax baileyi disturbance on plant community at alpine meadow in Three Rivers Headwater Region, China. Ying Yong Sheng Tai Xue Bao 29(6): 19021910.

2. Hong Jun, xinjiang, Lin Jun (2014) The natural grassland pest analysis and its prevention and control. Chinese Journal of grassland (3): 1-4.
3. Yang K, Li XD, Xu GW, Wei L, Meerburg BG (2016) Control of Eospalax baileyi (Plateau Zokor) with arrow traps in western China. Pakistan J Zool 48(1): 125-129.

4. Baldwin RA, Meinerz R, Orloff SB (2014) The impact of attractants on pocket gopher trapping. Current Zoology 60(4): 472-478.

5. Jojola SM, Witmer GW, Burke PW (2009) Evaluation of attractants to improve trapping success of nutria on Louisiana coastal marsh. The Journal of Wildlife Management 73(8): 1414-1419. 